УДК 681.3

DOI: $10.31471 / 1993-9981-2018-2(41)-18-24$

\title{
МОДЕЛЮВАННЯ ЗАЛЕЖНОСТІ ЗМІНИ ПОТУЖНОСТІ СОНЯЧНИХ ПАНЕЛЕЙ ВІД КУТА ПАДІННЯ ПРОМЕНІВ
}

\author{
М. О. Слабінога*, Ю. М. Кучірка, О. С. Криницький, Н. М. Юрків \\ Івано-Франківський національний технічний університет нафти і газу, 76019, м. Івано-Франківськ, \\ вул. Карпатська, 15, mslabinoha@gmail.com, tel. +38 (0342) 50-45-21.
}

У роботі було проаналізовано сучасний стан та перспективи досліджень у галузі математичного моделювання технологічних процесів в контексті сонячної енергетики. Було розглянуто фізичні та математичні моделі сонячних панелей, а також розглянуто теоретичні основи перетворення енергії у сонячних панелях, які покладено в основу принципу їх функціонування. На основі проведеного аналізу в роботі було розроблена математичну модель залежності потужності сонячної панелі від кута повороту. Розроблена модель враховує температуру навколишнього середовища, температуру, що отримала панель у процесі функціонування, вплив вітру на температуру панелі, а також вплив часу доби, дня року, кутів нахилу панелі відносно сонця, можливостей світловідбивання оточуючого середовища. Також, в даній моделі враховується вплив характеристик самої панелі, та ії допоміжних елементів функціонування, на отримувану споживачем потужність. В роботі було проведено апробацію даної математичної моделі, результати якої вказують на можливість ऑiі застосування для моделювання функціонування панелі при різних характеристиках навколишнього середовища. Розроблене відповідне програмне забезпечення для генерування експериментальних даних залежності сили продукованого струму від кута нахилу панелі, позиції сонця, метеорологічних умов, світловідбиваючих властивостей поверхні, тощо. Сформовано висновки та визначено подальші перспективи щодо використання такого математичного та програмного забезпечення для вирішення наукових та практичних задач.

Ключові слова: сонячна енергетика, математична модель, позиція сонячних панелей, метеорологічні умови, програмне забезпечення, перевірка моделі.

В работе было проанализировано современное состояние и перспективы исследований в области математического моделирования технологических процессов в контексте солнечной энергетики. Были рассмотрены физические и математические модели солнечных панелей, а также рассмотрены теоретические основы преобразования энергии в солнечных панелях, которые положены в основу принципа их функционирования. На основе проведенного анализа в работе была разработана математическая модель зависимости мощности солнечной панели от угла поворота. Разработанная модель учитывает температуру окружающей среды, температуру, получившей панель в процессе функционирования, влияние ветра на температуру панели, а также влияние времени суток, дня года, углов наклона панели относительно солнца, возможностей светоотражения окружающей среды. Также, в данной модели учитывается влияние характеристик самой панели, и ее вспомогательных элементов функционирования, на получаемую потребителем мощность. В работе была проведена апробация данной математической модели, результаты которой указывают на возможность ее применения для моделирования функционирования панели при различных характеристиках окружающей среды. Разработано соответствующее программное обеспечение для генерирования экспериментальных данных зависимости силы производимого тока от угла наклона панели, позиции солнца, метеорологических условий, светоотражающих свойств поверхности, т. Сформированы выводы и определены дальнейшие перспективы по использованию такого математического и программного обеспечения для решения научных и практических задач.

Ключевые слова: солнечная энергетика, математическая модель, позиция солнечных панелей, метеорологические условия, программное обеспечение, проверка модели.

The paper analyzes the current state and prospects of research in the field of mathematical modeling of technological processes in the context of solar energy. The physical and mathematical models of solar panels were considered, as well as the theoretical bases of energy conversion in solar panels, which are the basis for the principle of their functioning, were considered.

On the basis of the analysis carried out, a mathematical model of the dependence of the power of the solar panel 
on the angle of rotation was developed. The developed model takes into account the ambient temperature, the temperature received by the panel during operation, the effect of wind on the temperature of the panel, as well as the influence of time of day, day of the year, angles of the panel relative to the sun, the possibilities of environmental reflection. Also, this model takes into account the influence of the characteristics of the panel itself, and its auxiliary elements of functioning, on the power received by the consumer. In the work, an approbation of this mathematical model was carried out, the results of which indicate the possibility of its application for modeling the functioning of the panel under various environmental characteristics. The corresponding software for generating experimental data on the strength of the current produced from the angle of the panel, the position of the sun, the meteorological conditions, the reflecting properties of the surface, $t$. The conclusions are formulated and further perspectives on the use of such mathematical and software solutions for solving scientific and practical problems are determined.

Keywords: solar energy, mathematical model, position of solar panels, meteorological conditions, software, model validation.

За останні десятиліття значні зусилля дослідників були зосереджені на альтернативних джерелах енергії, оскільки використання вугілля, нафти і природнього газу, як очікується, у майбутньому може бути недоступним, через їх вичерпність і порівняно низьку відтворюваність. Енергетична криза залишиться невирішеною, якщо не використовується ефективний підхід. Крім вивчення нових джерел енергіï, поточне споживання енергії має бути добре керованим 3 метою полегшення енергетичної проблеми. Такі технології, як фотоелектричні сонячні елементи (так звані сонячні батареї) є важливими для прогресу відновлювальних джерел енергії.

3i зростанням кількості сонячних електростанцій в Україні, актуальною задачею є попередні розрахунки доцільності встановлення сонячних панелей в заданій локації та розрахунок параметрів установки, що дозволили б досягти максимальної продуктивності. Таким чином, математичне моделювання процесу функціонування сонячних панелей, зокрема залежності продуктивності панелі від кута падіння сонячних променів, $є$ важливою науково-прикладною задачею.

Питанням моделювання процесу генерації сонячної електроенергії присвячена велика кількість робіт. Окремі 3 них враховують температурні ефекти [1], аналізують різницю між модельованими та експериментальними даними [2-4]. Результати моделювання виражаються в підвищенні точності вимірювання показників процесу генерації енергії [5] та підвищенні надійності обладнання [6].

Найбільш ефективним методом дослідження сонячних установок $є$ імітаційне моделювання, що дозволяє в порівнянні 3 натурними експериментами врахувати вплив на енергетичні характеристики сонячних установок великого числа параметрів i скоротити витрати часу i коштів на проведення необхідних розрахунків та досліджень.

Фотоелектрична (PV) модель генератора зазвичай заснована на електричних характеристиках, тобто, поточне значення напруги, комірки під різними рівнями випромінювання i при різній температурі комірки

В основу математичного моделювання була закладена класична модель фотоперетворювача 3 p-n переходом. Найважливішою характеристикою, за якою оцінюють сонячні панелі $\epsilon$ iï потужність. Потужність електричного струму - фізична величина, що характеризує швидкість передачі або перетворення електричної енергіï. За визначенням, електрична напруга - це відношення роботи, яку Електричне поле виконує при перенесенні пробного електричного заряду з точки А у точку В, до величини пробного заряду. Тобто, можна сказати, що електрична напруга дорівнює роботі 3 перенесення одиничного заряду 3 точки А до точки В. Іншими словами, за руху одиничного заряду ділянкою електричного кола, він виконує роботу, що чисельно дорівнює електричній напрузі на даній ділянці кола. Робота, яку виконують ці заряди за руху від початку ділянки кола до його кінця, дорівнює роботі всіх одиничних зарядів.

Потужність, за визначенням, - це робота за одиницю часу.

$$
P_{A B}=\frac{A}{\Delta t}
$$


де, А - виконана робота під час руху заряду 3 точки А до точки $\mathrm{B}$, a $\Delta \mathrm{t}-$ час за який виконувалась дана робота.

Для одиничного заряду на АB:

$$
P_{A B}=\frac{U}{\Delta t}
$$

де, U - напруга на ділянці АВ.

Для всіх перенесених зарядів на АВ:

$$
P_{A B}=\frac{U}{\Delta t} \cdot Q=U \cdot \frac{Q}{\Delta t}
$$

де, Q - перенесений заряд на ділянці АВ.

Оскільки струм це кількість зарядів за одиницю часу, тобто $I=\frac{Q}{\Delta t}$, то

$$
P_{A B}=U \cdot I
$$

Вважаючи час нескінченно малим, можна прийняти, що величини напруги та струму за цей час, теж зміняться нескінченно мало. Як підсумок можна сказати, що потужність сонячної панелі дорівнює добутку величин напруги та струму, які вона генерує.

Розглянемо детальніше напругу та силу продукованого струму.

Для початку візьмемо електричний струм. Електричний струм - упорядкований, спрямований рух електрично заряджених частинок. Він характеризується густиною та силою. Густиною струму називають векторну величину, що визначається, як величина заряду, яка протікає через одиничну площу за одиницю часу. Силою струму (в електротехніці - струмом), що протікає через провідник $з$ площею поперечного перерізу S називається величина, яка відповідає кількості заряду $\Delta \mathrm{q}$, переміщеному через переріз провідника за проміжок часу $\Delta \mathrm{t}$.

У міжнародній системі CI сила струму вимірюється в амперах (позначається: А). Відповідно, густина струму вимірюється в $\mathrm{A} / \mathrm{M}^{2}$.

Зважаючи на закон Ома, потужність можна виразити наступний чином:

$$
P=I \cdot I \cdot R
$$

де I - електричний струм на виході сонячної панелі, R - опір шунта.
Опір шунта це незмінна величина, яка не буде змінюватись, чи пї зміни будуть незначними під час роботи сонячної панелі, тому їі можна вважати константою.

Формула для струму буде мати наступний вигляд[7]:

$$
I=I_{\text {Ф.С. }}-I_{\text {насичения }}
$$

де $I_{\text {Ф.С. }}$ - фотострум, $I_{\text {насичения }}-$ струм насичення.

Струм насичення також буде незмінним в процесі роботи сонячної панелі, він задається виробником, в залежності від iї конструкції, матеріалу, способів з'єднання комірок панелі.

Фотострум розраховується наступним чином[8]:

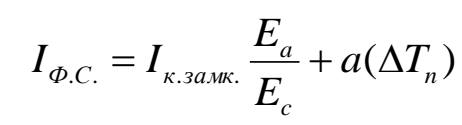

де $I_{\text {кзамк. }}$ - струм короткого замикання холостого ходу панелі, $E_{a}-$ сонячна інсоляція, яку отримує панель, Вт/м², $E_{c}-$ сонячна інсоляція при нормальних умовах роботи $\left(1000 \mathrm{BT} / \mathrm{M}^{2}\right), a-$ температурний коефіцієнт струму, $\Delta T_{n}-$ різниця наявної температури сонячної панелі від нормальної.

Для початку, варто розглянути вплив температури на струмоутворення в сонячній панелі. На температуру панелі мають вплив температура навколишнього середовища, величина отримуваної сонячної інсоляції, а також вітер, що обдуває панель, і навіть при його відсутності, вона буде віддавати тепло в навколишне середовище за умови, що навколишнє середовище менш нагріте ніж панель. Зважаючи на те, що зміну струму буде приносити власне різниця температури від нормальної, формула для знаходження цієї різниця буде наступною[9]:

$$
\Delta T_{n}=E_{a} \cdot e^{c+b \cdot \vartheta_{\theta}}+T_{a}-T_{H . y .}
$$

де $T_{\text {н.y. }}$ - нормальна температура, $25^{\circ} \mathrm{C}, T_{a}-$ температура навколишнього середовища, ${ }^{\circ} \mathrm{C}$, $c$ - коефіцієнт, що встановлює максимальну температуру панелі при низькій швидкості вітру, $b-$ коефіцієнт, що враховує зміну 
температури при високій швидкості вітру, $\vartheta_{\beta}-$ швидкість вітру, м/с. Власне коефіцієнт с можна вважати коефіцієнтом пасивної передачі тепла навколишньому середовищу, оскільки тепло передається без роботи вітру.

$$
E_{a}=E_{n p .} \cdot \frac{\cos \varepsilon}{\cos \theta}+E_{\text {роз. }} \cdot \frac{(1+\cos \beta}{2}+\rho\left(E_{n p .}+E_{\text {роз. }}\right) \cdot \frac{1-\cos \beta}{2}
$$

де $E_{n p}$ - інтенсивність прямого сонячного випромінювання, Вт/м², $E_{\text {роз. }}-$ інтенсивність розсіяного сонячного випромінювання, Вт/м², $\rho$ - коефіцієнт відбиття поверхонь (альбедо), $\beta$ - нахил панелі до горизонту, град, $\varepsilon-$ кут панелі між нахилом на Сонце та нормаллю, град, $\theta$ - кут панелі між нахилом на Сонце та зенітом, град. Як можна побачити з формули, сонячна інсоляція впливає на струмоутворення на панелі двома способами, перший це при прямому сонячному випромінюванні, другий - при розсіяному. Тому можна стверджувати, що продукована потужність панелі також буде залежати від навколишнього середовища та об'єктів, їхнього коефіцієнта відбиття сонячного випромінювання.

Кут нахилу панелі між сонцем і нормаллю можна вирахувати наступним чином:

$$
\begin{aligned}
& \cos \varepsilon=\sin (\varphi-\beta) \cdot \sin \delta+ \\
& +\cos (\varphi-\beta) \cdot \cos \delta \cdot \cos \omega
\end{aligned}
$$

де $\varphi$ - широта місцевості, в град., $\beta$ - нахил сонячної панелі до горизонту, в град., $\delta$ нахил сонця, розраховується за формулою Купера, в град., $\omega$ - часовий кут руху Сонця, в град.

Кут нахилу панелі між сонцем і зенітом можна розрахувати наступним чином:

$$
\cos \theta=\sin \delta \cdot \sin \varphi+\cos \delta \cdot \cos \varphi \cdot \cos \omega(11)
$$

Тепер розглянемо детальніше формулу Купера. Значення нахилу Сонця, яке позначається як $\delta$, зазнає сезонні зміни. Це відбувається через те, що Земля рухається по еліптичній орбіті навколо Сонця, а так само через нахилу іiі власної осі обертання. Якби вісь обертання Землі не була нахилена, схиляння було постійно рівним 0. Як би там не було, вона нахилена на $23.45^{\circ}$ і кут нахилу
Залишилось сонячне випромінювання, яке має найбільший вплив на струмоутворення в сонячній панелі, та формула сонячної інсоляції має наступний вигляд:[10]

приймає значення від $23.45^{\circ}$ до $-23.45^{\circ}$. Кут нахилу стає рівним нулю два рази в рік в дні весняного i осіннього рівнодення. Сама формула має вигляд:

$$
\delta=23,45^{\circ} \cdot \sin \left[\frac{360}{365}(d-81)\right]
$$

де $d$ - день року, (1 січня = 1).

Відхилення дорівнює нулю в дні рівнодення (22 березня i 22 вересня), позитивно, коли в північній півкулі літо i негативно, коли там зима. Максимуму, рівного $23.45^{\circ}$ схиляння досягає 22 червня (літнє сонцестояння в північній півкулі) і мінімуму, $23.45^{\circ}, 22$ грудня (зимове сонцестояння в північній півкулі).

В підсумку модель потужності сонячної панелі показує, що частина впливових показників залежить від виробника, 3 якою якістю він виготовить панель, якою чистотою буде володіти кремній в панелі, та ін. Такі показники не будуть зазнавати великих змін на протязі року i, відповідно, змінювати свій вплив на потужність панелі. Інші показники, до яких належать швидкість вітру, температура навколишнього середовища, кути нахилу панелі, альбедо навколишнього середовища, сонячна інсоляція, мають безпосередній вплив на роботу сонячної панелі. Власне сонячне випромінювання має найбільший вплив на струмоутворення в сонячній панелі і тому на їі потужність.

Для апробації розробленої моделі необхідно виконати розрахунки за даною моделлю, а також 3 допомогою програми, що моделює роботу сонячної панелі. Програмне забезпечення для моделювання було розроблено в середовищі GNU/Octave. До його переваг можна віднести: ліцензія розповсюдження - GNU GPL, сумісність програмного коду GNU Octave 3 MATLAB, модуль побудови графіків і поверхонь. GNU 
Octave працює 3 величезними масивами (100 000 елементів) і матрицями (більше 1000 000) елементів. Крім того, GNU/Octave володіє набором інструментів для проведення багаторазового імітаційного моделювання, зокрема декілька класів генераторів псевдорандомних чисел в різних діапазонах та за різними законами розподілу.

При моделюванні у програмі даної математичної моделі, на усіх можливих кутах повороту панелі до сонця,

Для проведення розрахунків обрано сонячну панель Bosch Solar Module c-Si M 60, а також наступні дані:

$$
\begin{aligned}
& I_{\text {насичення }}=0,56, \mathrm{~A} ; \\
& I_{\text {к.замк. }}=8,92, \mathrm{~A} ; \\
& a=0,00031, \mathrm{~A} / K ; \\
& \varphi=48^{\circ} ;
\end{aligned}
$$

$$
\begin{aligned}
& \rho=0,15 ; \\
& E_{n p .}=500 \mathrm{BT} / \mathrm{M}^{2} ; \\
& E_{\text {роз. }}=250 \mathrm{BT} / \mathrm{M}^{2} ; \\
& T_{a}=30{ }^{\circ} \mathrm{C} ; \\
& \mathrm{c}=-3,473 ; \\
& \mathrm{b}=-0,0594 ; \\
& \vartheta_{\text {o }}=5 \mathrm{M} / \mathrm{c} .
\end{aligned}
$$

Змінними залишились нахил сонячної панелі до горизонту, нахил сонця, часовий кут руху Сонця. Проведено 5 розрахунків струму за розробленою математичною моделлю та в програмі, що моделює сонячну панель.

у першому випадку було випадково обрано наступні значення:

$$
\delta=46 ; \omega=35 ; \beta=8 \text {. }
$$

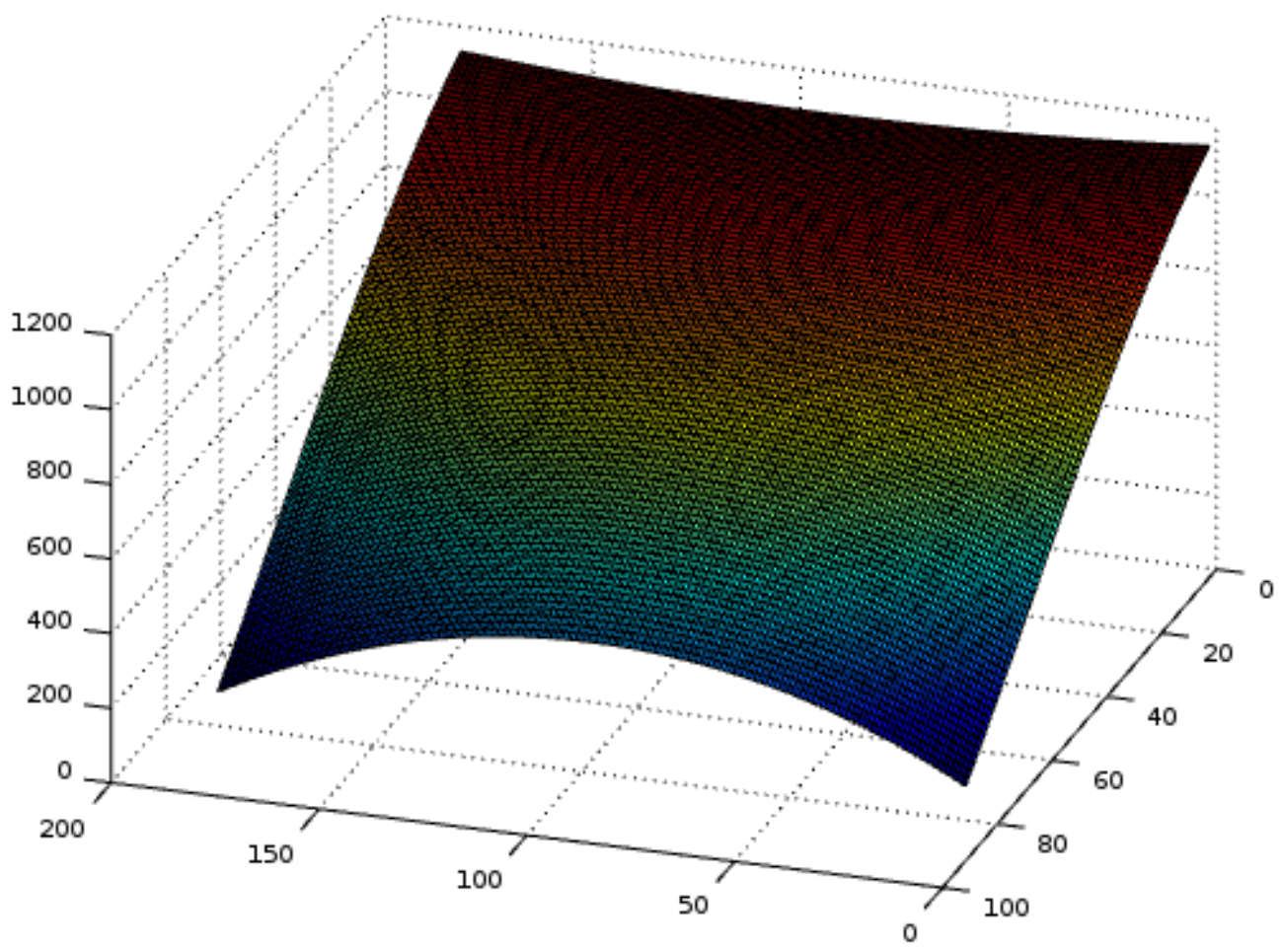

Рисунок 1 - Графік залежності сонячної інсоляції від кутів нахилу панелі до Сонця

При моделюванні за допомогою програми отримано наступне значення струму за формулою (7):

$$
I_{n p}=4,3364-0,56=3,7764, \mathrm{~A} \text {. }
$$

При розрахунку 3 допомогою розробленої моделі струм становив:

$$
I_{M}=4,3367-0,56=3,7767, \mathrm{~A} .
$$

У другому випадку було випадково обрано наступні значення: 
$\delta=44 ; \omega=-76 ; \beta=17$.

При моделюванні за допомогою програми отримано наступне значення струму:

$$
I_{n p}=3,5789-0,56=0,0189, \mathrm{~A} .
$$

При розрахунку з допомогою розробленої моделі струм становив:

$$
I_{M}=3,5788-0,56=0,0188, \mathrm{~A} .
$$

У третьому випадку було випадково обрано наступні значення:

$\delta=37 ; \omega=-38 ; \beta=78$.

При моделюванні за допомогою програми отримано наступне значення струму:

$$
I_{n p}=1,5201-0,56=0,9601, \mathrm{~A} .
$$

При розрахунку з допомогою розробленої моделі струм становив:

$$
I_{M}=1,5202-0,56=0,9602, \mathrm{~A} .
$$

У четвертому випадку було випадково обрано наступні значення:

$\delta=79 ; \omega=-70 ; \beta=82$.

При моделюванні за допомогою програми отримано наступне значення струму:

$$
I_{n p}=0,93673-0,56=0,37673, \mathrm{~A} .
$$

При розрахунку з допомогою розробленої моделі струм становив:

$$
I_{M}=0,93673-0,56=0,37673, \mathrm{~A} .
$$

У п'ятому випадку було випадково обрано наступні значення:

$\delta=70 ; \omega=63 ; \beta=4$.

При моделюванні за допомогою програми отримано наступне значення струму:

$$
I_{n p}=5,1877-0,56=4,6277, \mathrm{~A} .
$$

При розрахунку з допомогою розробленої моделі струм становив:

$$
l_{M}=5,1876-0,56=4,6276, \mathrm{~A} .
$$

Для підтвердження правильності результатів моделювання визначимо адекватність моделі:

$$
\begin{gathered}
\sigma=\sqrt{\frac{\sum\left(I_{M}-I_{n p}\right)^{2}}{n-1}} \\
\sigma=0,00017 \mathrm{~A} .
\end{gathered}
$$

Достовірність математичної моделі розраховується за формулою:

$$
R=1-\frac{\sum\left(I_{M}-I_{n p}\right)^{2}}{\sum\left(I_{M}^{2}\right)-\frac{1}{n} \sum\left(I_{M}\right)^{2}}
$$

$$
R=0.99 \text {. }
$$

Отже, на основі отриманих результатів очевидним $\epsilon$ те, що програмне забезпечення 3 достатньою точністю описує струмоутворення в сонячних панелях і може застосовуватись для виконання розрахунків.

Отримане програмне забезпечення може бути використане при дослідженні ефективності алгоритмів покоординатного пошуку максимуму та застосовуватися в подальшому для програмного забезпечення 3 моделювання роботи сонячних панелей, обладнаних системами слідкування за сонцем. Отримані результати доцільно також порівняти 3 експериментальними даними в контексті схожості результатів роботи алгоритмів та методів дослідження роботи сонячних панелей на експериментальних та математично змодельованих даних.

Публікація містить результати досліджень, проведених при грантовій підтримці Держаного фонду фундаментальних досліджень за конкурсним проектом Ф83.

1. D. King, J. Kratochvil, and W. Boyson, "Temperature Coefficients for PV Modules and Arrays: Measurement Methods, Difficulties, and Results," 26th IEEE PV Specialists Conference, 1997, pp. 1183-1186.

2. Clauser, J. F. (1974). Experimental distinction between the quantum and classical field-theoretic predictions for the photoelectric effect. Phys. Rev. D 9: 853-860.

3. В. Г. Литовченко, Б. М. Романюк, В. Г. Попов, В. П. Мельник, О. С. Оберемок, В. П. Кладько, І. П. Лісовський, В. В. Стрельчук, В. В. Черненко, В. О., «Шаповалов Комплексні дослідження кристалічного матеріалу для сонячної енергетики», Металлофиз. новейшие технол. / Metallofiz. Noveishie Tekhnol. 2011p, m. 33, № 7, cc. 873-898.

4. В. М. Коваль, «Розрахунок зонного моделю нанокристалічного кремнію», Наносистеми, наноматеріали, нанотехнології 2009p, m. 7, № 4, cc. 987-998. 
5. D. King, W. Boyson, and B. Hansen, "Improved Accuracy for Low-Cost Solar Irradiance Sensors," 2nd World Conference on PV Solar Energy Conversion, Vienna, 1998, pp. 2001-2004.

6. D. King, T. Hund, W. Boyson, and J. Kratochvil, "Experimental Optimization of the Performance and Reliability of Stand-Alone Photovoltaic Systems," 29th IEEE PV Specialists Conference, 2002.

7. Б.Н.Шарифов Т.Р.Терегулов, «Моделирование солнечной панели 6 программе MATLAB/Simulink», ISSN 1992-6502 2015. T. 19, № 4 (70). C. 77-83.

8. А.М.Треш, «Моделирование солнечных батарей в среде matlab/simulink».

9. А.М. Пенджиев, Н.Г. Астанов, «Исследования мобильной солнечной фотоэлектрической станции в зависимости от ориентации» Наука. Мысль: электронный периодический журнал № 6-2. - 2016р.

10. D.L. King, W.E. Boyson, J.A. Kratochvill, «Photovoltaic Array Performance Model», SANDIA REPORT SAND2004-3535 Unlimited Release Printed December 2004.

Поступила в редакцію 22.11.2018 p.

Рекомендували до друку: докт.техн.наук, проф. Костишин В. С., докт. техн. наук, проф. Середюк О. С. 